\title{
Occurrence and seasonal distribution of polycyclic aromatic hydrocarbons and legacy and current-use pesticides in air from a Mediterranean coastal lagoon (Mar Menor, SE Spain)
}

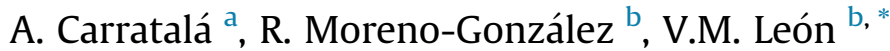 \\ ${ }^{a}$ Departamento de Ingeniería Química, Universidad de Alicante, Spain \\ ${ }^{\mathrm{b}}$ Instituto Español de Oceanografía, Centro Oceanográfico de Murcia, Apdo. 22, C/ Varadero 1, 30740 San Pedro del Pinatar, Murcia, Spain
}

\section{H I G H L I G H T S}

- PAHs, legacy and CUPs were analyzed in air using active and passive sampling devices.

- 28 compounds (PAHs, PCBs and pesticides) were found in coastal air samples.

- Chlorpyrifos, chlorpyrifos-methyl and phenanthrene were the most commonly detected.

- The highest concentrations for PAHs and some herbicides were found in winter.

- The highest concentrations for insecticides were found in autumn.

\section{A R T I C L E I N F O}

\section{Article history:}

Received 29 July 2016

Received in revised form

21 September 2016

Accepted 30 September 2016

Handling Editor: R Ebinghaus

\section{Keywords:}

PAHs

Pesticides

Active sampling

Passive air sampling

Seasonal distribution
G R A P H I C A L A B S T R A C T

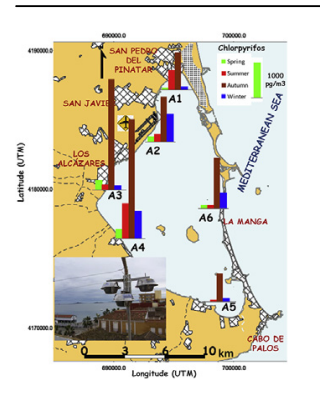

\begin{abstract}
A B S T R A C T
The occurrence and seasonal distribution of polycyclic aromatic hydrocarbons (PAHs) and legacy and current-use pesticides (CUPs) in air were characterized around the Mar Menor lagoon using both active and passive sampling devices. The seasonal distribution of these pollutants was determined at 6 points using passive samplers. Passive sampler sampling rates were estimated for all detected analytes using an active sampler, considering preferentially winter data, due to probable losses in active sampling during summer (high temperatures and solar irradiation). The presence of 28 compounds (14 CUPs, 11 PAHs and 3 organochlorinated pesticides) were detected in air by polyurethane passive sampling. The most commonly detected contaminants ( $>95 \%$ of samples) in air were chlorpyrifos, chlorpyrifos-methyl and phenanthrene. The maximum concentrations corresponded to phenanthrene $\left(6000 \mathrm{pg} \mathrm{m}^{-3}\right)$ and chlorpyrifos $\left(4900 \mathrm{pg} \mathrm{m}^{-3}\right)$. The distribution of contaminants was spatially and seasonally heterogeneous. The highest concentrations of PAHs were found close to the airport, while the highest concentrations of pesticides were found in the influence area of agricultural fields (western stations). PAH and herbicide concentrations were higher in winter than in the other seasons, although some insecticides such as chlorpyrifos were more abundant in autumn. The presence of PAHs and legacy and current-use pesticides in air confirmed their transference potential to marine coastal areas such as the Mar Menor lagoon.
\end{abstract}

(C) 2016 Elsevier Ltd. All rights reserved.

\footnotetext{
* Corresponding author

E-mail address: victor.leon@mu.ieo.es (V.M. León).
} 